\title{
Development and Manufacture of Cost Effective Composite Drill Pipe
}

\section{Annual Technical Progress Report File Name:40262R20.pdf}

Reporting Period Start Date: October 1, 2002

Reporting Period End Date: September 30, 2003

Principal Authors: Dr. James C. Leslie, CEO, ACPT, Inc. Mr. James C. Leslie II, President, ACPT, Inc. Mr. Lee Truong, Engineering Manager, ACPT, Inc. Mr. James T. Heard, Program Manager, ACPT, Inc.

Report Issue Date: March 30, 2003

DOE Cooperative Agreement No: DE-FC26-99FT40262

Submitting Organization:

Advanced Composite Products and Technology, Inc. (ACPT) 15602 Chemical Lane Huntington Beach, CA 92649

Ph: (714) 895-5544

Fx: (714) 895-7766 


\subsection{DISCLAIMER}

This report was prepared as an account of work sponsored by an agency of the United States Government. Neither the United States Government nor any agency thereof, nor any of their employees, makes any warranty, express or implied, or assumes any legal liability or responsibility for the accuracy, completeness, or usefulness of any information, apparatus, product or process disclosed, or represents that its use would not infringe privately owned rights. Reference herein to any specific commercial product, process, or service by trade name, trademark, manufacturer, or otherwise does not necessarily constitute or imply its endorsement, recommendation, or favoring by the United States Government or any agency thereof. The views and opinions of authors expressed herein do not necessarily state or reflect those of the United States Government or any agency thereof. 


\subsection{ABSTRACT}

This technical report presents the engineering research and data accomplishments that have transpired to date in support of the development of Cost Effective Composite Drill Pipe (CDP). The report presents accomplishments made from October 1, 2002 through September 30, 2003. The following have been accomplished and are reported in detail herein:

- Metal-to-Composite Interface (MCI) redesign and testing

- Successful demonstration of MCI connection for both SR and ER/DW CDP

- Specifications for a $127 \mathrm{~mm}$ (5") ID by $152.4 \mathrm{~mm}$ (6") OD composite drill pipe have been finalized for Extended Reach/Deep Water applications (ER/DW).

- $\quad$ Field testing of Short Radius CDP (SR)

- Sealing composite laminate to contain high pressure

- Amendments

- Amendment for "Smart" feature added to ER/DW development along with time and funding to complete battery of qualification tests with option for field demonstration.

- Preparation of papers for publication and conference presentations. 


\subsection{TABLE OF CONTENTS}

1.0 DISCLAIMER

2.0 ABSTRACT

$\begin{array}{lll}3.0 & \text { TABLE OF CONTENTS } & 4\end{array}$

4.0 LIST OF GRAPHICAL MATERIALS

$\begin{array}{llc}5.0 & \text { INTRODCUTION } & 6\end{array}$

6.0 EXECUTIVE SUMMARY $\quad 6$

$\begin{array}{lll}7.0 & \text { EXPERIMENTAL } & 7\end{array}$

$\begin{array}{lll}\text { 7.1. } & \text { Task } 1 \text { Mechanical Requirements } & 7\end{array}$

$\begin{array}{lll}\text { 7.2. } & \text { Task } 2 \text { - Electrical and Magnetic Specifications } & 8\end{array}$

7.3. Task 3 Physical Requirements 9

7.4. Task 4 Progress Report 9

7.5. Task 5 Laboratory Testing 9

7.6. Task 6 "Field Testing" 9

7.7. Task 7 Second Year Technical Reporting 9

7.8. $\quad$ Task 8 Test Samples and Preliminary Drill Pipe Sections $\quad 10$

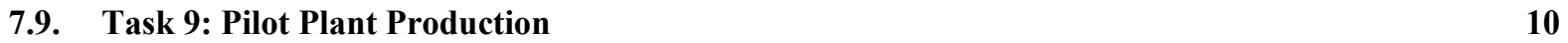

7.10. Task 10: Design and Develop Wire through Wall of ER/DW CDP 10

7.11. Task 11: Design Direct Electrical Connection Field Prototype for ER/DW CDP 10

7.12. Task 12: Qualification Testing of Smart ER/DW CDP 10

7.13. Task 13: Final Report $\quad 10$

$\begin{array}{lll}8.0 & \text { RESULTS AND DISCUSSION } & 10\end{array}$

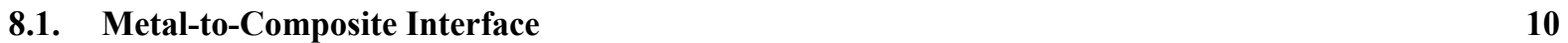

8.2. $\quad$ Redesign SR CDP Delivered to JB Drilling 12

8.3. Field Testing of Short Radius CDP $\quad 13$

\begin{tabular}{ll} 
8.4. & Sealing Composite Laminate \\
\hline
\end{tabular}

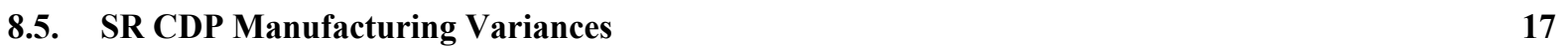

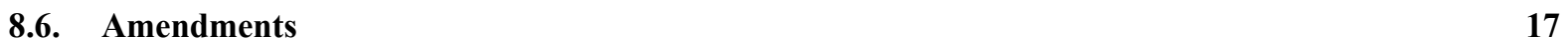

8.7. Papers, Conferences and Presentations 18

$\begin{array}{lll}9.0 & \text { CONCLUSION } & 18\end{array}$

$\begin{array}{lll}10.0 & \text { REFERENCES } & 18\end{array}$

11.0 LIST OF ACRONYMS AND ABBREVIATIONS 19 


\subsection{LIST OF GRAPHICAL MATERIALS}

Figure 1 SR CDP Tension Test........................................................... 11

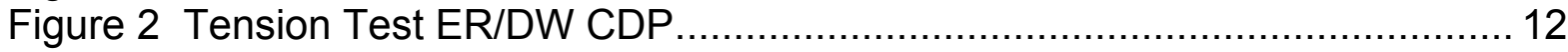

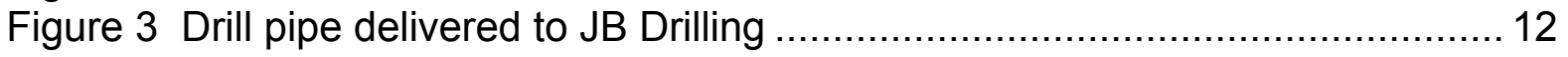

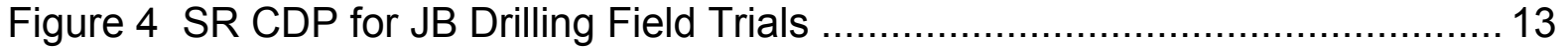

Figure 5 Lincoln versus ACPT ................................................................ 14

Figure 6 SR CDP Field Trials with Grand Resources ................................... 15

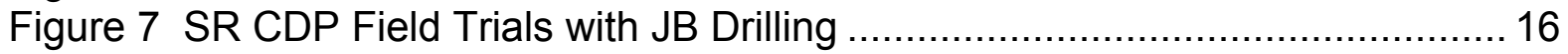




\subsection{INTRODCUTION}

This writing assumes the reader has prior knowledge of this contract and the progress, development issues and technical hurdles within this program. To learn more of the history and detail of prior work and efforts it is recommended that reader refer to prior year annual reports (40262R5, 40262R10, 40262R15).

The objective of this contract is to develop and demonstrate "cost effective" Composite Drill Pipe. It is projected that this drill pipe will weigh less than half of its steel counter part. The resultant weight reduction will provide enabling technology drastically increasing the lateral distance that can be reached from an offshore drilling platform and the depth of water in which drilling and production operations can be carried out. Further, composite drill pipe has the capability to carry real time signal and power transmission within the pipe walls. CDP can also accommodate much shorter drilling radius than is possible with metal drill pipe. As secondary benefits the lighter weight drill pipe can increase the storage capability of floating off shore drilling platforms and provide substantial operational cost savings.

This co-operative agreement was awarded September 30, 1999 and has been amended nine times. The current amendment A009 has an end date of January 30, 2005. The original contract consisted of ten major tasks of which eight have been substantially completed. Three additional tasks were added to include the development and field demonstration of Short Radius CDP as a result of early development successes and at the request of the industry. The SR CDP is intended for land based well re-entry and directional drilling activities. The SR CDP development is completed and will be made commercially available in 2004. Amendment A008 was awarded September 30, 2003 to include the development of a "Smart" feature demonstrated earlier in the project and to complete developmental qualification testing and field demonstrations of the ER/DW CDP.

\subsection{EXECUTIVE SUMMARY}

Design and Analysis remains a continuous effort throughout the DOE contract and is an integral part of all ongoing CDP manufacturing operations. Initial work concentrated on specifying the requirements for a "typical" drill pipe which when converted to the capabilities of composites would enable extended reach and "deeper" water drilling. These requirements have continually been refined during this program and are constantly upgraded as experience with the use and manufacture of CDP is obtained. The goal remains to further extend the reach for horizontal drilling and enable drilling into even deeper water.

Specifications have been prepared, reviewed and finalized for a $127 \mathrm{~mm}$ (5") inside diameter Composite Drill Pipe. This increase in diameter from the original specifications came about for two primary reasons: 1) Industry partners (Omsco and Chevron/Texaco) had expressed concerns about hydraulic losses in the $114.3 \mathrm{~mm}$ (4.5") design, but the design of that pipe was limited by the MCI geometry and process of manufacturing. The inside diameter of the pipe body was at its maximum in the current design; 2) The wind in place tool joint process proved to be extremely difficult to control and produced a wide variance in test results. It was concluded that if ACPT had trouble with the manufacturing processes it would never be commercialized on a large scale. The maximum tension test results only reached 2,224,111 Newtons (500,000 pound) ultimate load, while the goal has remained at about 2,668,933 
Newtons (600,000 pounds). In order to reach that goal the MCI had to be modified to accommodate an additional $20 \%$ tensile load. The redesign of the MCI set out to accomplish making the CDP "manufacturing friendly", capable of increased tensile loads and increase the inside diameter of the pipe. These goals have been met with the new MCI design.

The new MCI design was first developed and tested on the SR CDP. Results were $160 \%$ of goal. Based on these results, the MCI for ER/DW CDP were developed and tested. Initial results were $106 \%$ of goal. Full scale tests of both $3.05 \mathrm{~m}\left(10^{\prime}\right)$ and $9.1 \mathrm{~m}\left(30^{\prime}\right)$ sections of the $127 \mathrm{~mm}$ (5") CDP have been planned and scheduled. Based on the tension test results, which is considered the controlling parameter, this design iteration is expected to exceed all specification requirements (tension, torque, pressure and compression).

Two additional drilling companies, Grand Resources of Tulsa, OK and JB Drilling of Fort Smith, AR were referred to ACPT by DOE/NETL to explore a cooperative arrangement in which ACPT will furnish 8 sections and 9 sections of SR CDP respectively, for use in field testing on air and air hammer drilling applications. DOE/NETL also requested 3 additional sections of SR CDP to be delivered to Terra drilling for additional field testing in Texas. ACPT submitted a proposal to DOE/NETL on 8/27/2002 to include additional funding for these tests. Amendment A005 was issued 9/9/02 to include these field tests in this cooperative agreement.

\subsection{EXPERIMENTAL}

\subsection{Task 1 Mechanical Requirements}

Task I is substantially complete. Defining the mechanical requirements for CDP has been and continues to be an on going effort. The mechanical specifications currently in use for design and manufacture of CDP are as follows:

\subsubsection{Extended Reach/Deep Water Product Data}

\subsubsection{Mechanical Specifications}

Bending Stiffness

Torsional Stiffness

Axial Stiffness

Rated Tension Load

Rated Torsion Load

Rated Compression Load

Rated Internal Pressure

Max Service Temperature
EI

GJ

EA

$\mathrm{P}$

$\mathrm{T}$

$P_{c}$

$P_{i}$

F
$180 \times 10^{6} \mathrm{lb}-\mathrm{in}^{2}$

$115 \times 10^{6} \mathrm{lb}^{\mathrm{in}}{ }^{2}$

$33.4 \times 10^{6} \mathrm{lb}$

$450,000 \mathrm{lbs}$

$25,000 \mathrm{ft}-\mathrm{lb}$

$250,000 \mathrm{lbs}$

$9,500 \mathrm{psi}$

$350^{\circ} \mathrm{F}$

\subsubsection{Physical Specifications}

Tube Inside Diameter

Tube Outside Diameter

Length (Pin-to-Box)

Centralizers

Weight
ID

OD

L

LB
5 in

6 in

360 in (30 ft)

5 equally spaced

$375 \mathrm{lbs}$ 


\subsubsection{Connection Specifications}

$\begin{array}{lll}\text { Pin/Box Diameter } & \text { OD } & 7 \text { in } \\ \text { Bore } & \text { ID } & 5 \text { in } \\ \text { Thread } & \text { IF } & \text { NC } 56 \text { or Customer Spec }\end{array}$

\subsubsection{Short Radius Product Data}

\subsubsection{Mechanical Specifications}

Bending Stiffnes E

Torsional Stiffness

Axial Stiffness

Rated Tension Load

Rated Torsion Load

Rated Compression Load

Rated Internal Pressure

Max Service Temperature

$\mathrm{P}$

T

F
EI

GJ

$\mathrm{AE}$

$\mathrm{P}_{\mathrm{c}}$

$\mathrm{P}_{\mathrm{i}}$

ID

OD

Pipe Outside Diameter

Length (Pin-to-Box)

Centralizers

Weight

$\begin{array}{lc}\mathrm{EI} & 7.22 \times 10^{6} \mathrm{lb}^{-\mathrm{in}^{2}} \\ \mathrm{GJ} & 11.30 \times 10^{6} \mathrm{lb}^{2} \mathrm{in}^{2} \\ \mathrm{AE} & 14.30 \times 10^{6} \mathrm{lb} \\ \mathrm{P} & 25,000 \mathrm{lbs} \\ \mathrm{T} & 2,000 \mathrm{ft}-\mathrm{lb} \\ \mathrm{P}_{\mathrm{c}} & 50,000 \mathrm{lbs} \\ \mathrm{P}_{\mathrm{i}} & 1,000 \mathrm{psi} \\ \mathrm{F} & 325^{\circ} \mathrm{F}\end{array}$

$15 / 8$ in

$21 / 2$ in

360 in (30 ft)

5 equally spaced

$92 \mathrm{lbs}$

$33 / 8$ in

$15 / 8$ in

$\mathrm{NC} 26$ or customer spec

\subsubsection{Materials of Construction}

Pipe body

Std Tool Joints

Non-magnetic Tool Joints

Wear Knots
OD

ID

IF
Filament wound E-glass/Graphite/Epoxy

$4140 \mathrm{HT}$ steel

Stainless steel, Monel or customer spec

Nitrile

\subsubsection{Availability}

Price and delivery is quoted upon request. Length and diameter can be scaled to customer requirements. Mechanical properties can be customized to suit application.

\section{2. $\quad$ Task 2 - Electrical and Magnetic Specifications}

Task 2 has been completed. CDP can carry power and/or real time communications through lines embedded in the composite walls. This program was empowered to investigate the feasibility of accomplishing these ends. Initial discussions with industry experts combined with in house knowledge of composites provide a different view of providing LWD/MWD capabilities in the CDP. In summary: 1.) Signal and power can be transmitted through the composite walls. 2.) The problem to be solved is reliably 
transmitting signal or power through the metal joints connecting the individual CDP sections.

A direct connect prototype was demonstrated to the DOE-NETL in Morgantown in August of 2002. Maurer and ACPT prepared and submitted a proposal to demonstrate practicality and reduce this concept to practice. This has now become Task 10 and Task 11 in Amendment A008 of the contract.

\subsection{Task 3 Physical Requirements}

This work complete and the results are included in the Section 7.1. This is also an ongoing effort and the physical requirements will be updated as more actual drilling experience is obtained and as longer reach, deeper water capabilities are defined.

\subsection{Task 4 Progress Report}

Task 4 is completed. A first year report was presented at NETL in Morgantown on $8 / 31 / 01$.

\subsection{Task 5 Laboratory Testing}

Laboratory testing is essentially complete. Task 5 included:

- Screening and verification of mechanical properties of resins, fibers, and adhesives for design and fabrication of CDP.

- Temperature and Environmental Resistance of all material to be used in the CDP.

- Measurement of Erosion and Mechanical Abrasion characteristics of interior and exterior coatings for CDP.

- Future work will be conducted in these areas to evaluate possible improvements for the CDP as currently designed.

\subsection{Task 6 "Field Testing"}

\subsubsection{Field Testing of $1-5 / 8$ " CDP}

All field testing of SR CDP will be accomplished by use in drilling short radius wells. This task is essentially complete with the completion of Grand Resources and JB drilling field trials. This product is being readied for a commercial release.

\subsubsection{Field Testing of 5" CDP}

The planned field testing of ER/DW CDP is now an optional add-on to the program depending on the outcome of Task 12 Qualification Testing of Smart ER/DW CDP.

\section{7. $\quad$ Task 7 Second Year Technical Reporting}

An oral presentation of the accomplishments of this program was made at the NETL/DOE facilities in Morgantown, WV on 8/20/01. The report has been filed with DOE/NETL AAD Document Control. Task 7 is complete. 


\section{8. $\quad$ Task 8 Test Samples and Preliminary Drill Pipe Sections}

This is ongoing as test specimens are continuing to be produced in support of tasks 10,11 and 12 .

\subsection{Task 9: Pilot Plant Production}

All Pilot Plant production will be performed at ACPT. The existing facilities have modified to accommodate Task 9.

\subsection{Task 10: Design and Develop Wire through Wall of ER/DW CDP}

This task was amended with A008 of the contract and just awarded September 30, 2003.

It has been sub-contracted to Noble Downhole Technology, Ltd.

\subsection{Task 11: Design Direct Electrical Connection Field Prototype for ER/DW CDP}

This task was amended with A008 of the contract and just awarded September 30, 2003. It has been sub-contracted to Noble Downhole Technology, Ltd.

\subsection{Task 12: Qualification Testing of Smart ER/DW CDP}

This task was amended with A008 of the contract and just awarded September 30, 2003. It is ongoing and concurrent with tasks 10 and 11.

\subsection{Task 13: Final Report}

A final report will be prepared in accordance with contract requirements.

\subsection{RESULTS AND DISCUSSION}

\subsection{Metal-to-Composite Interface}

The tension test results were not meeting expectations or design parameters. ACPT believed that winding the metal end fitting in place was causing too much band gap thus reducing the strength of the finished part. The collars wound into place were tweaked (dimensionally) to obtain the best fit possible; however, the design and process did not meet the program goals. The following tests were conducted at Coordinated Equipment:

○ 9-4-2002 ultimate failure at 1,272,191 N (286,000 lbs).

- 11-11-2002 bond broke at 1,338,915 N (301,000 lbs).

○ 12-9-2002 ultimate failure at 1,805,978 N (406,000 lbs).

Results from tension tests predicated a new MCI design that increased the tension capacity with repeatable results thereby eliminating manufacturing variances. The new design details are considered proprietary to ACPT, Inc. and are not disclosed in this report. This new design has solved the problems described herein. This same design is being applied to the SR CDP as well to eliminate the chronic manufacturing problems of winding the tool joints in place as revealed from field test results. This was done for five primary reasons: 
1. Winding in place over the tapered hump presented unacceptable results with fiber placement (band gaps, compaction and bridging), is difficult to set up (material handling) and presented sealing problems.

2. Four consecutive tensile test results were well below design target

3. Mandrel extraction was very difficult and resulted in failure $33 \%$ of the time (pipe collapsed or mandrel destroyed)

4. New design allows flexibility to accommodate a range of ID/OD sizes on same tool joint.

5. Is scalable for larger or smaller pipe sizes and tool joints.

Two tensile tests were conducted on short length ER/DW CDP with the new MCI in January. The first test attained an ultimate of 1,912,735 N (430,000 pounds). The second test attained an ultimate of 2,046,182 N (460,000 pounds). We also completed a tensile test on the SR CDP with the new MCI that attained an ultimate of $542683 \mathrm{~N}(122,000$ pounds) (goal is $333,617 \mathrm{~N}$ (75,000 lbs.). Based on the SR test results, the new ER/DW MCI was modified to model the SR geometry and new test specimens were manufactured for additional tensile tests. These new specimens also have a larger inside diameter and are $127 \mathrm{~mm}$ (5") ID by $152 \mathrm{~mm}$ (6") OD with $178 \mathrm{~mm}$ (7") tool joints.

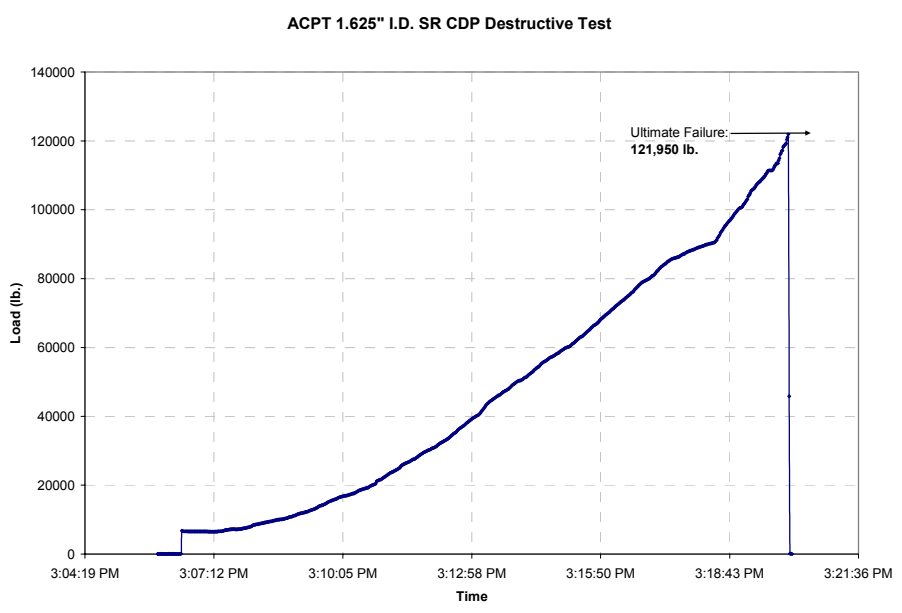

Figure 1 SR CDP Tension Test

Two tensile tests on $3 \mathrm{~m}$ (10ft) long ER CDP with the new MCI and geometry were conducted in March 2003. The first test specimen had a bond line thickness that deviated from design requirements due to assembly problems and failed the tensile test at $2,192,973 \mathrm{~N}$ (493,000 pounds). The second specimen achieved an ultimate tensile load of 2,651,140 N (596,000 pounds), which exceeds the target of 2,504,349 N (563,000 pounds). With this success, the program is proceeding with qualifying the design for pressure, compression and torque. 


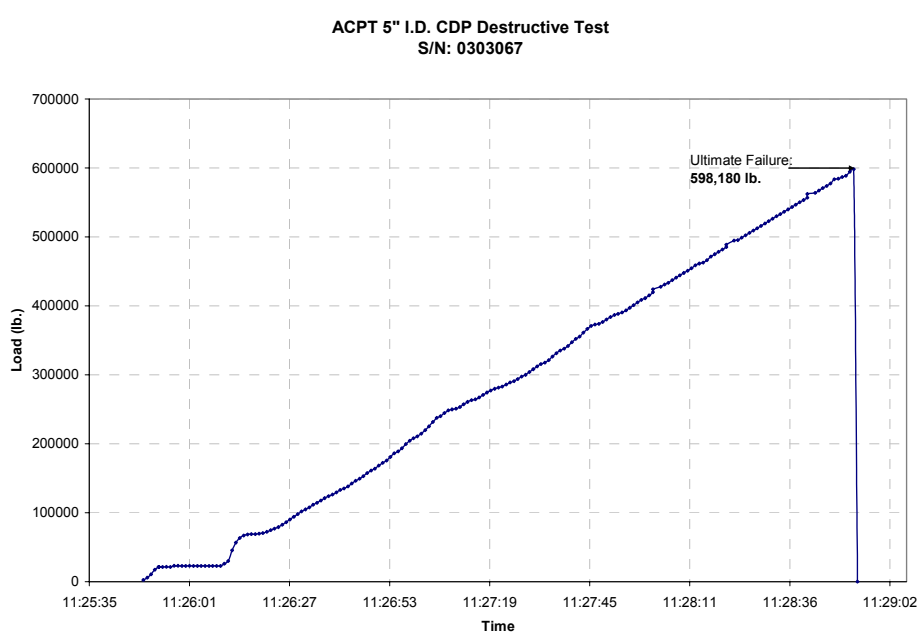

Figure 2 Tension Test ER/DW CDP

\subsection{Redesign SR CDP Delivered to JB Drilling}

Based on the SR tensile test results with the new MCI, 9 full length SR CDP joints were manufactured and delivered to JB Drilling for field testing with air hammer tools (see Figure 4). The pipe was shipped to JB Drilling in April 2003. JB Drilling conducted field trials from June $12^{\text {th }}$ through June $17^{\text {th }}$ with the SR CDP using air hammer tools. The pipe worked flawlessly until the wear knots inflated with air and plugged the well. The solution was to perforate the wear knots so they could continue using pipe, but the ultimate solution is to develop adequate laminate sealing materials and processes. (See Figure 7). Overall, the testing was successful and the experience adds to the commercial viability of the product. With the successful field test by JB Drilling, we will seek opportunities to sell small quantities of the Short Radius CDP.

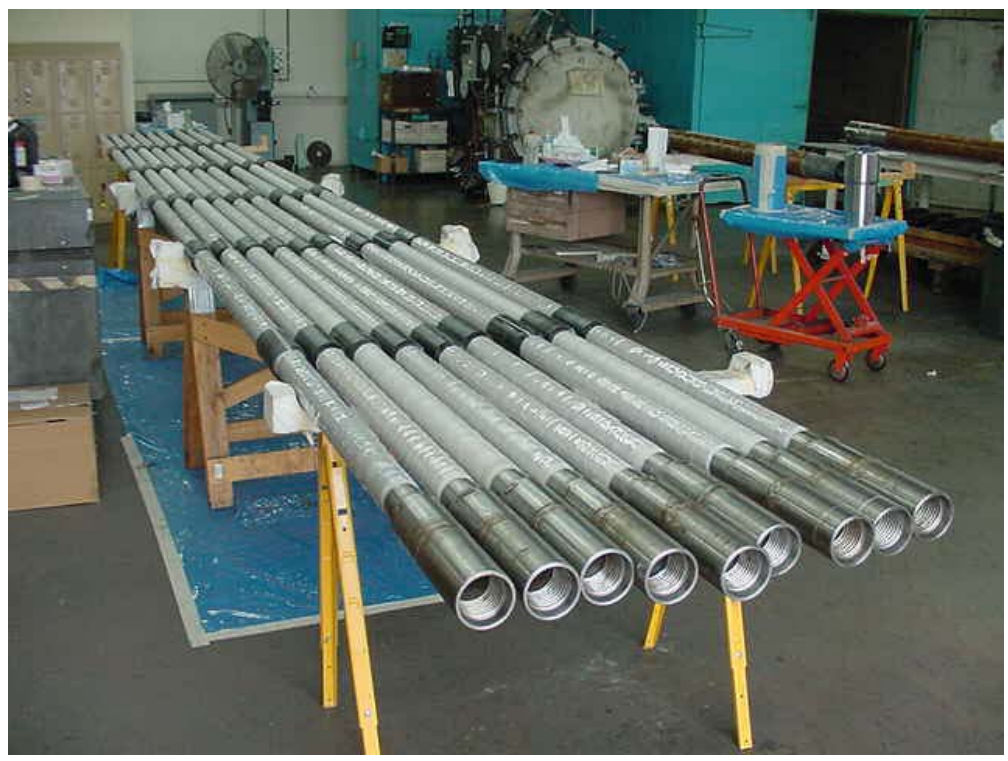

Figure 3 Drill pipe delivered to JB Drilling 


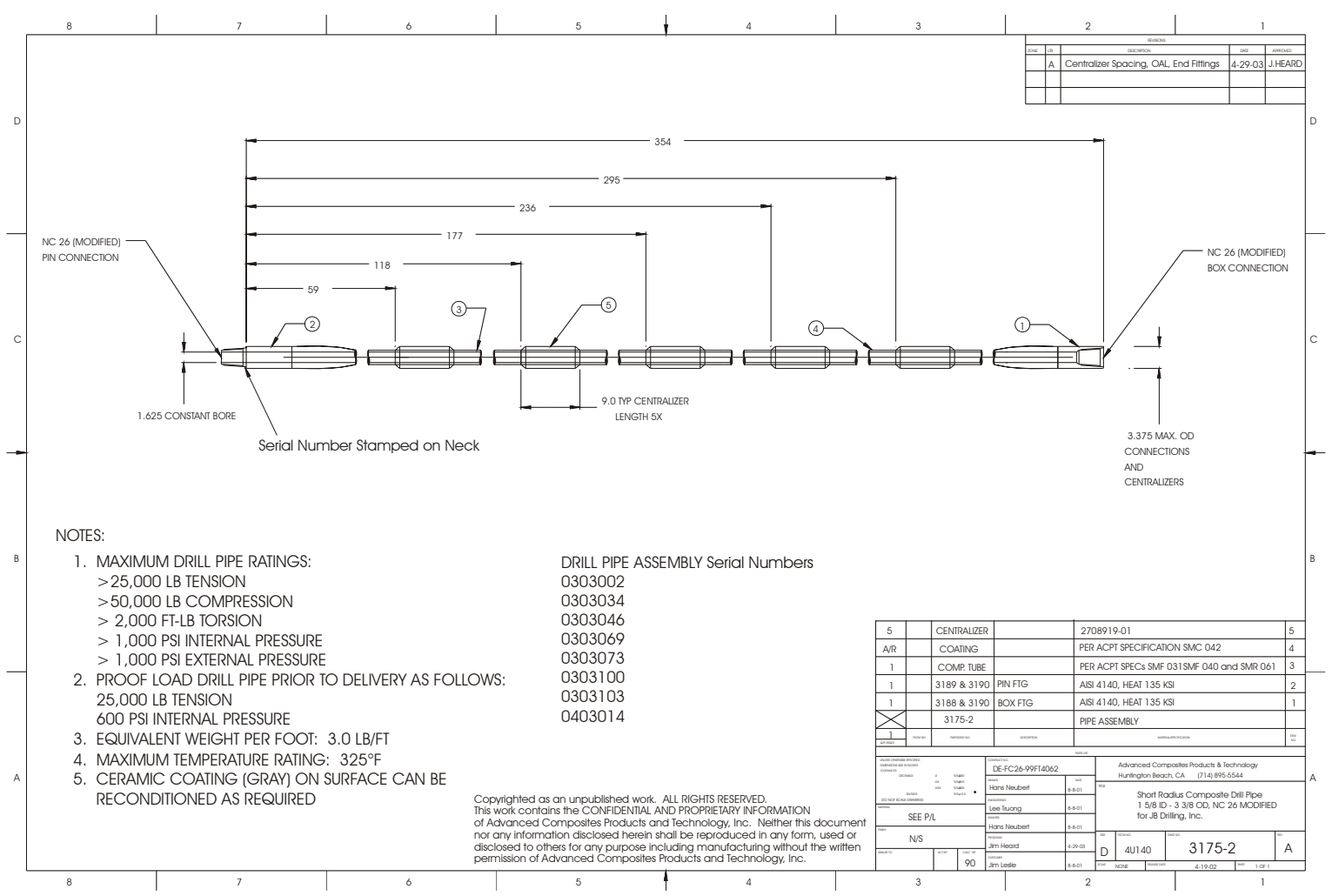

Figure 4 SR CDP for JB Drilling Field Trials

\section{3. $\quad$ Field Testing of Short Radius CDP}

Three sections of the wind in place MCI SR CDP were delivered to Terra in Oman and eight sections were delivered to Grand Resources in OK for field trials.

\subsubsection{Grand Resources Field Test}

Grand Resources first field test was conducted 11-6-2003 with oversized diameter pipe. They were concerned about stiffness of tool joints because of length of metal pin and box joints. They believed the pipe would be too stiff and metal joints too long for less than $15 \mathrm{~m}$ (50') radius. Second test conducted on 12-17-2002 with new smaller OD pipe. Grand Resources reported the pipe was "perfect", but suffered a failure of the MCI on 18-2003.

Excerpt form letter to Grand Resources 10-16-2002:

Below is a photograph comparing Lincoln Composites' pipe to ACPT's composite pipe. The ACPT pipe has a larger ID (1.63 vs 1.50). The Box joint is counter bored to increase flow efficiency, reduce weight and stiffness and makes room for grabbing tools. The Lincoln pipe employs a sleeve to provide enough area to grab, but also adds to the joints stiffness. Compounded with the stress riser at the end of the joint, the Lincoln pipe would fail at a larger "drilling" radius than the ACPT pipe. The bending stiffness transition is better with the ACPT pipe than Lincoln's is, i.e., more gradual. The ACPT pipe is made from all carbon fiber while Lincoln's pipe is predominantly fiberglass. Carbon fiber has far greater fatigue resistance and modulus than fiberglass. 
The ACPT pipe design has undergone extensive static testing for torsion, tension and pressure. We feel confident that the pipe will perform to the ratings we have assigned to it. Grand Resources agreed to test the pipe dynamically by drilling with it in exchange for 8 sections. The current end fitting design cannot be modified without first having field test results.

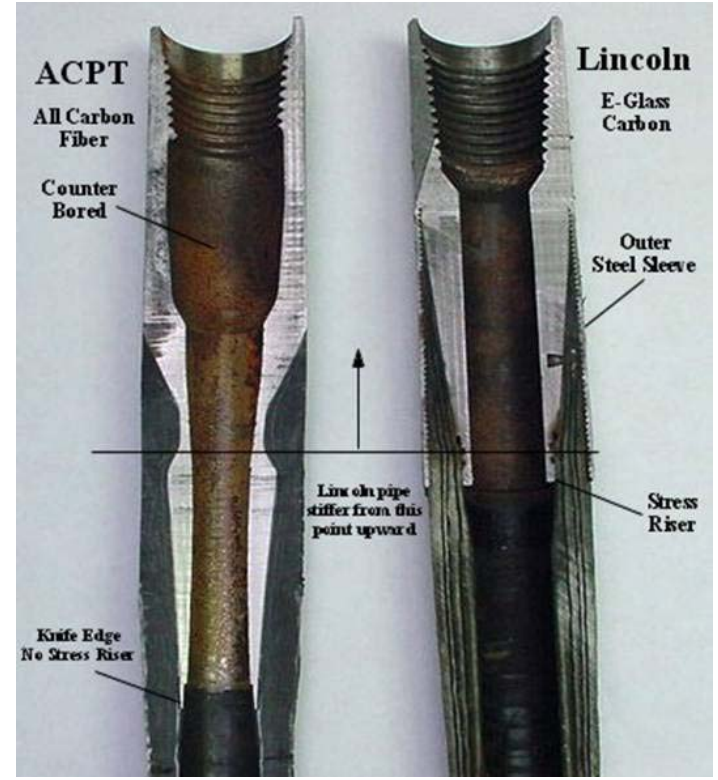

Figure 5 Lincoln versus ACPT 


\subsubsection{First Field Test Press Release \\ First Field Test of SR CDP Proves Successful}

Tulsa County, Oklahoma was the site of the first field test of the Short Radius Composite Drill Pipe (SR CDP) developed by ACPT, Inc. in cooperation with the U.S. Department of Energy, National Energy Technology Laboratory. The field test was completed on November 6, 2002 by Grand Resources, Inc. at their Bird Creek site. Starting with an existing well that stopped producing in 1923, Grand Resources packed the bottom of the well and sealed it with concrete. Then they lowered the drill string 1208 feet and began drilling a $70 \mathrm{ft}$. radius curvature through the well casing and into the formation. The SR CDP was furnished by ACPT, Inc. and DOE/NETL for the purpose of drilling the curve and lateral section which extends 1000 feet into the strata. The pipe worked flawlessly and Grand Resources was pleased with performance of the new product.

Grand Resources estimates that this renewed well will produce 30 to 50 barrels of oil per day for quite some time. Grand Resources plans to renew 14 additional wells in the same area in the near future and will use the new composite drill pipe in these endeavors.

The CDP was not used to drill the lateral portion of this well because air hammer tools were used for this section. Grand Resources will test sections of CDP with air hammer tools in the next well. The air hammer beats at 2400 strokes per minute with a 4 to 6 inch stroke. This will be a good test of the strength and durability of the CDP. As they gain experience and confidence in the product, Grand Resources expects to extend the reach from 1000 to 2000 feet by using the CDP with air hammer technology.

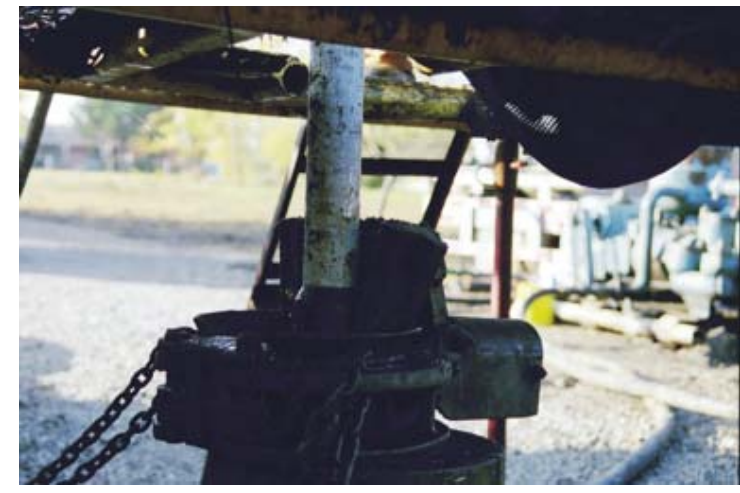

\section{SR CDP going down hole}

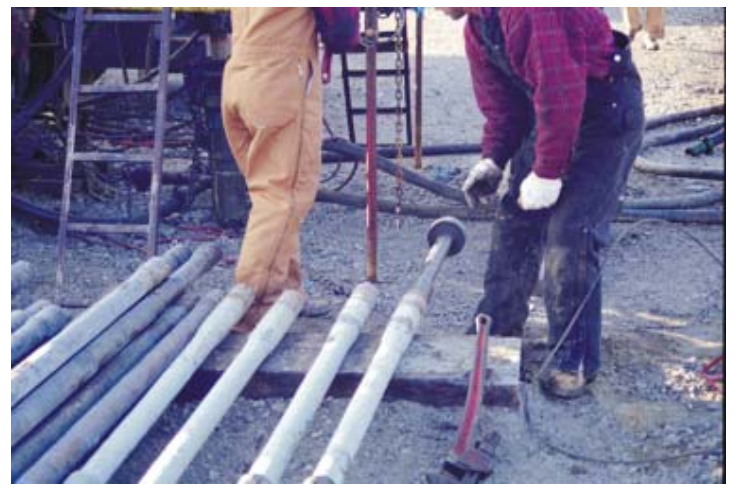

SR CDP being readied for lifting

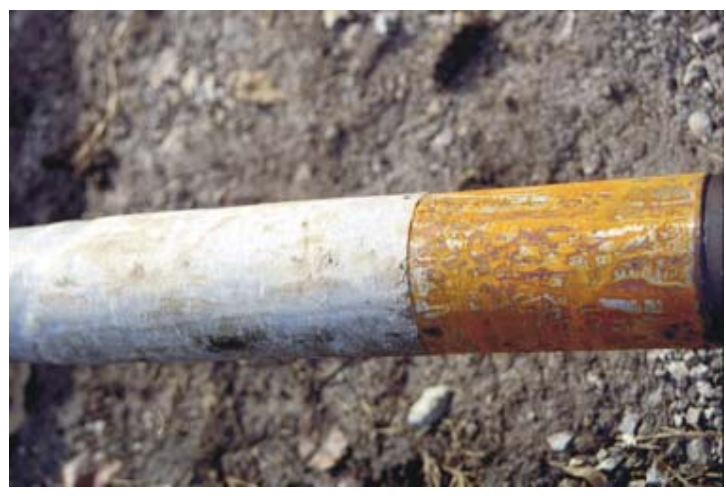

Condition of joint end after use a little rust on the steel end, but the composite has only a few scratches.

Figure 6 SR CDP Field Trials with Grand Resources 


\subsubsection{Second Field Test Press Release Short Radius Composite Drill Pipe Strikes a Blow for Natural Gas Production}

JB Drilling, Inc. successfully used composite drill pipe in short radius, horizontal drilling operations conducted from June 12th through June 17th, 2003 in Leflore County, OK. Horizontal Systems, Inc. of Casey, IL provided the steering technology and services. Rambler Energy Services, Inc. (Enid, OK) furnished the drilling rig and crew. A new natural gas well was drilled to a depth of 1385 feet. Then a 60 foot radius and a 1000 foot lateral would be attempted through hard sandstone. This is the second successful group of field trials of the Short RadiusComposite Drill Pipe (SR-CDP) manufactured by ACPT, Inc. and developed under a cooperative agreement with the U. S. Department of Energy, National Energy Technology Laboratory. Industry partners include Zoltek, Omsco and Chevron/Texaco.

This group of field trials had two primary goals. First, the SRCDP was being used with air-hammer drilling tools to give the pipe a real pounding and test its fatigue life and mechanical strength. Along with the pounding, the formation was very hard and abrasive which was an excellent test of the protective coatings used on the pipe. The second goal was to develop steering techniques and drill bit geometry for use with an air-hammer to increase the rate of penetration and make it more economical to recover natural gas from the hard formations typical of the Arkoma Basin. The first goal was achieved while significant progress was made on the second goal. JB Drilling is planning another trial and test in October of 2003.

The Arkoma Basin was formed millions of years ago from a river delta 90 miles wide. The fine marine sediments accumulated and were compressed forming a hard sandstone containing gas hydrates and trapped methane. The well is being drilled into a fracture zone formed by plate tectonics. These fractures and hydrates release methane which is what JB Drilling intends to collect.

Five, 30-foot joints of SR-CDP were run for a total of more than 160,000 cycles at an average RPM of 70, air pressure of $300 \mathrm{psi}$, and torque of $1000 \mathrm{lb}$-ft. The pipe was subjected to momentary over pulls of 12,000 pounds, 10,000 pounds compression and $1500 \mathrm{lb}$-ft of torque. After a week of drilling, the pipe showed little to no signs of wear. Three sections were sent back to ACPT for closer examination and study. It was concluded that this version of the SR-CDP design will be released commercially as fatigue data continues to accumulate.

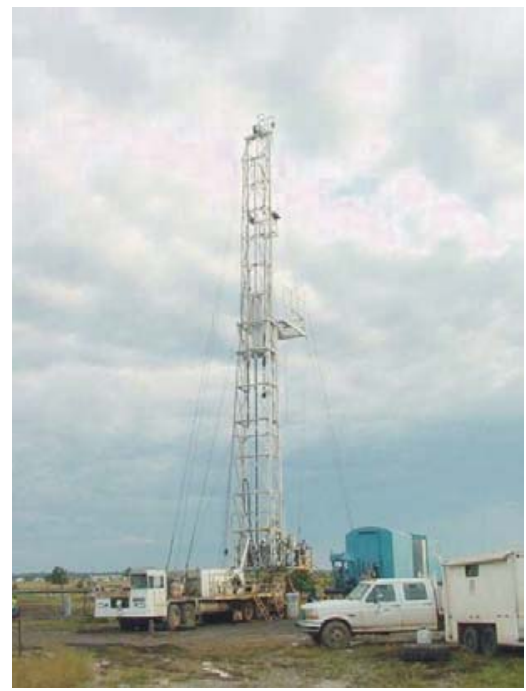

Well Site: French 4-4, Leflore County, OK 100 ft. High Drill Rig operated by Rambler Energy Services.

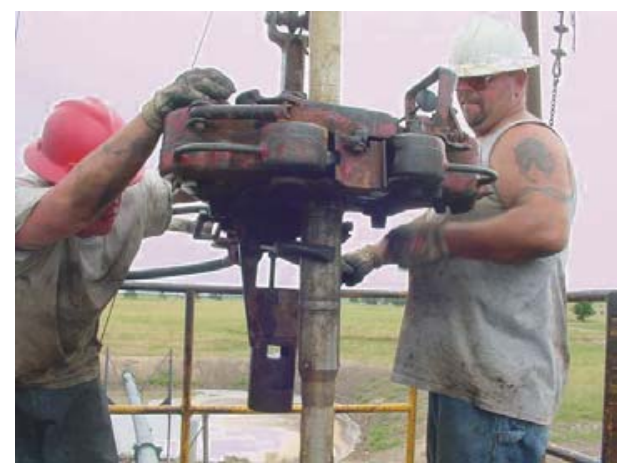

Short Radius Composite Drill Pipe being added to the drill string.

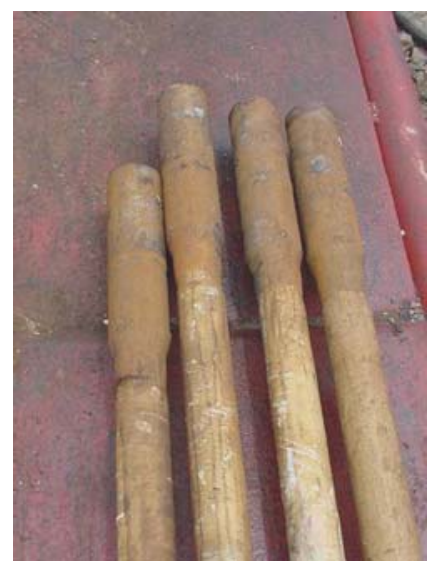

After 160,000 cycles, the pipe exhibits little to no signs of wear.

Figure 7 SR CDP Field Trials with JB Drilling 


\subsection{Sealing Composite Laminate}

There has been consistent weeping of water through the composite wall during hydrostatic and field tests. In an effort to seal the pipe wall permanently the many approaches were considered and/or tried. Since the conclusion of these experiments is considered proprietary to ACPT, Inc. further details will not be revealed in this report. Suffice it to say that several solutions are viable and continued research and process developments are needed to solve this item completely.

\section{5. $\quad$ SR CDP Manufacturing Variances}

- Solved winding discrepancies

The laminate wall thickness was not meeting design parameters. The finished part was too thick, which created a $56 \%$ increase in stiffness (E*I) than designed. The laminate design and materials were reviewed and the winding machine was reprogrammed accordingly.

- Buckling during mandrel extraction

The SR CDP had repeated failures during mandrel extraction. The length of the steel end fittings (tool joints) caused the mandrel to jam on the end fitting. The ID was honed to open up clearances, but the process was time consuming and expensive. Also, too much clearance allowed resin to seep in and bond the mandrel to the end fitting, which caused the fitting to bind on the mandrel as well. The composite pipe would then collapse in compression and would have to be scrapped.

- Broken mandrels

In several cases where the composite pipe did not collapse, the mandrel was pulled apart.

The new MCI has eliminated most incidents of failure during mandrel extraction, as the entire length of the mandrel does not have to be pulled though the tool joint.

\subsection{Amendments}

This co-op agreement with the DOE was scheduled to end April 30, 2003. Since a field demonstration with the ER CDP was not completed by that time, the completion date was extended to July 30, 2003 (Amendment M006). It was unlikely that all the required testing would be completed by July 30, 2003 and DOE requested ACPT to submit a proposal to extend the program to complete this task. This proposal was submitted May $9^{\text {th }}$ 2003. Funding was consumed by the end of July 2003. ACPT submitted a proposal to extend the contract in order to complete development and qualification testing and to include development of a "Smart" feature and conduct a field demonstration.

This co-op agreement with DOE was then scheduled to end September 30, 2003 (Amendment M007). DOE requested a proposal to extend the contract to include development of Smart Extended Reach CDP and conduct a field demonstration. This proposal was submitted and awarded September 30, 2003. Completion date is January 30, 2005. 


\subsection{Papers, Conferences and Presentations}

Leslie, J.C., Composite Drill Pipe an Enabling Technology for Extended Reach and Deep Water Drilling, Gas Technology Institute's First Conference and Exhibition on Natural Gas Technologies, Orlando, Florida, October 2002.

Leslie, Dr. J.C.; Jean, J.R., Heard, J.T.; Truong, L ; Neubert, H ; 2002 Annual Technical Progress Report "Cost Effective Composite Drill Pipe; DOE/NETL Report No. 40262R $15 ;$ 9/20/2002

Leslie, J.C., Developing a Cost Effective Composite Drill Pipe, "Gas Tips", Hart/IRI Fuels Information Services, Winter 2002, Volume 8, Number 1.

Leslie, J.C., Composite Drill Pipe-An Enabling Technology for Extended Reach and Deep Water Drilling, MRO3-263, SME, Dearborn, MI, WESTEC 2003, Los Angeles, CA, March 2003.

Leslie, J.C., New Composite Drill Pipe Offers Advantages for Short Radius, Extended Reach/Deep Water, and Deep Trek Operations, GTI Natural Gas Technologies II, Phoenix, Arizona, February 2004.

Leslie, Dr. J.C.; Heard, J.T.; Truong, L; Leslie, J.C. II; 2003 Annual Technical Progress Report "Cost Effective Composite Drill Pipe; DOE/NETL Report No. 40262R20; $3 / 30 / 2004$

\subsection{CONCLUSION}

ACPT is approaching the first steps of commercializing the SR CDP. The press releases over the last year have generated a lot of interest in this product along with some inquiries for price, delivery, etc. To date it has been stressed that the product is currently only available for experimental field testing. Successful field tests with JB Drilling may induce sales of small quantities of SR CDP.

Development and testing, to date, indicate that the ER/DW CDP as currently designed will meet or exceed all mechanical and physical requirements as shown in Section 7.1.1 of this report. This conclusion will be proven through planned laboratory and field testing.

ACPT and Noble Downhole Technology development effort now underway will demonstrate the practicality or non-effective nature of the current direct electrical contact, data/power, through wall transmission design intended to make the pipe "Smart".

\subsection{REFERENCES}

1. Leslie, Dr. J.C.; Jean, J ; Truong, L ; Neubert, H ; and Leslie, J.C. II; 2000 Annual Technical Progress Report "Cost Effective Composite Drill Pipe; DOE/NETL Report No. 40262R05; 10/30/2000 
2. Leslie, Dr. J.C.; Jean, J ; Truong, L ; Neubert, H ; 2001 Annual Technical Progress Report "Cost Effective Composite Drill Pipe"; DOE/NETL Report No. 40262R10; $10 / 30 / 2001$

3. Leslie, Dr. J.C., Composite Drill Pipe for Extended-Reach and Deep Water Applications, Paper \#14266, Offshore Technology Conference, Houston, Texas, May 2002

4. Leslie, Dr. J.C., Composite Drill Pipe an Enabling Technology for Extended Reach and Deep Water Drilling, Gas Technology Institute's First Conference and Exhibition on Natural Gas Technologies, Orlando, Florida, October 2002.

5. Leslie, Dr. J.C.; Jean, J.R., Heard, J.T.; Truong, L ; Neubert, H ; 2002 Annual Technical Progress Report "Cost Effective Composite Drill Pipe; DOE/NETL Report No. 40262R15; 9/20/2002

6. Leslie, Dr. J.C., Developing a Cost Effective Composite Drill Pipe, "Gas Tips”, Hart/IRI Fuels Information Services, Winter 2002, Volume 8, Number 1.

7. Leslie, Dr. J.C. ; Jean, J ; Truong, L ; Neubert, H ; and Leslie, J. II. ; "Cost Effective Composite Drill Pipe: Increased ERD, Lower Cost Deepwater Drilling and Real Time LWD/MWD Communications"; SPE Paper No. 67764 ; SPE/IADC Conference ; The Netherlands, 2/27-3/1/01.

\subsection{List of Acronyms and Abbreviations}

\section{ACPT}

Advanced Composite Products and Technology, Inc., 1

CDP

Composite Drill Pipe, 3

DOE

U.S. Department of Energy, 6

ER/DW

Extended Reach/Deep Water, 3

MCI

Metal-to-Composite Interface, 3

SR

Short Radius, 3 